
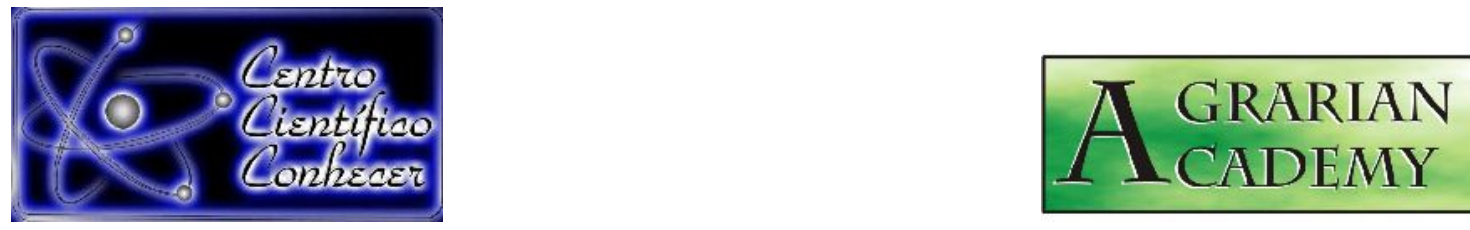

\title{
DESENVOLVIMENTO INICIAL DA SOJA EM FUNÇÃO DA UTILIZAÇÃO DE DIFERENTES DOSES DE NPK
}

\author{
Cicero Aritana Wilton Ferreira ${ }^{\text {* }}$, Érich Vinícius Nogueira Gonçalo ${ }^{2}$, Laura Leopoldina \\ Sousa $^{2}$, Nerton da Penha Filho ${ }^{2}$, Felipe Thomaz da Camara ${ }^{3}$ \\ 1 Graduando em Engenharia Agronômica da Universidade Federal do Cariri \\ (wiltonaritana@gmail.com), Crato-Brasil; \\ 2 Graduando em Engenharia Agronômica, Universidade Federal do Cariri; \\ 3 Dr., Prof. Adjunto CCAB, Universidade Federal do Cariri.
}

Recebido em: 14/07/2018 - Aprovado em: 28/07/2018 - Publicado em: 31/07/2018 DOI: 10.18677/Agrarian_Academy_2018a17

\begin{abstract}
RESUMO
Atualmente, o Brasil se destaca mundialmente como o segundo maior exportador e produtor de grãos de soja. Recentemente a soja vem se destacando como uma cultura que tem a maior área cultivada e determinante para a expansão da fronteira agrícola. Neste sentido, o presente trabalho teve como objetivo avaliar o desenvolvimento inicial da cultura da soja em função de diferentes doses de fertilizante N-P-K (nitrogênio, fósforo e potássio), com o intuito de determinar a melhor dose, de maneira que permita um melhor aproveitamento dos nutrientes pela planta na fase de desenvolvimento inicial. O delineamento experimental utilizado foi o de blocos casualizados, com quatro tratamentos e oito repetições. Os tratamentos consistiram em quatro doses de N-P-K aplicados na semeadura da soja, com valores de 0, 25, 50 e 100\% da dose recomendada para a cultura. As variáveis avaliadas foram comprimento da raiz, altura da planta, número de folhas, massa da parte aérea, da raiz e massa total, sendo coletadas cinco plantas para análise. Os dados foram tabulados e submetidos à análise de variância e à análise de regressão para seleção do maior expoente significativo, foi utilizado o programa estatístico SISVAR 5.3. Dentre as variáveis avaliadas, a variável número de folhas apresentou resultado significativo a $5 \%$. Para a análise de regressão, obtiveram resposta significativa a massa da parte aérea e total da planta e o número de folhas, com melhores resultados para a aplicação entre 50 e $60 \%$ da dose recomendada.
\end{abstract}

PALAVRAS-CHAVE: Adubação; Fertilizante; Glycine max.; 


\title{
INITIAL DEVELOPMENT OF SOYBEAN IN THE USE OF DIFFERENT DOSES OF NPK
}

\begin{abstract}
Currently, Brazil stands out worldwide as the second largest exporting and producer of soya beans. Recently soy has been highlighting as a culture that has the largest cultivated area and determinant for the expansion of the agricultural frontier. In this sense, the objective of the present work was to evaluate the initial development of soybean culture on different doses of N-P-K (nitrogen, phosphorus and potassium) fertilizer, with the purpose of determining the best dose of fertilizers, in a way that enable a better utilization of the nutrients by the plant in the initial development phase. The experimental lineation used was the randomized blocks, with four treatments and eight repetitions. The treatments consisted of four doses of N-P-K applied in soybean seeding, with values of $0,25,50$ and $100 \%$ of the recommended dose for the crop. The evaluated variables were root length, plant height, number of leaves, mass aerial of the root and total mass, being collected five plants for analysis. The data were tabulated and submitted to the analysis of variance and regression analysis for the selection of the largest significant exponent, it was used the statistical program SISVAR 5.3. Among the evaluated variables, the variable number of leaves, showed a significant result of $5 \%$. For the regression analysis, they obtained the mass of the aerial part and plant total, and number of leaves with best result for application between 50 e $60 \%$ of recommended dose.
\end{abstract}

KEYWORDS: Fertilizer; Fertilizing; Glycine max;

\section{INTRODUÇÃO}

O Brasil, na atualidade, vem se destacando mundialmente por ser o segundo maior exportador e produtor de grãos de soja. Recentemente a soja vem se destacando como uma cultura que tem a maior área cultivada e determinante para a expansão da fronteira agrícola (AMARAL; RODRIGUES, 2015). No Nordeste, uma região que vem obtendo destaque é o estado da Bahia, que na safra de 2016 possuía uma área plantada de aproximadamente, 1,52 bilhões de hectares e uma produção de cerca de 3,21 bilhões de toneladas, ao mesmo tempo em que a área plantada nacionalmente era de, aproximadamente, 33,2 bilhões de hectares, com uma produção de, aproximadamente, 96,02 bilhões de toneladas (SANTOS et al., 2017).

Uma das inovações na produção mundial de alimentos foi o uso de fertilizantes, proporcionando, assim, o aumento da produtividade. No mercado, são ofertados diversos produtos, com diferentes formas químicas, eficiência, granulometria e de diversos nutrientes (FIORIN et al., 2016).

Um dos maiores importadores de fertilizantes do mundo é o Brasil, além disso, é o quarto maior consumidor. Os fertilizantes solúveis liberam os nutrientes de forma acelerada, atendendo assim as exigências nutricionais das plantas cultivadas de forma rápida, deste modo se faz necessário buscar fertilizantes que possuam tanto macro como micronutrientes, e que essencialmente apresente um baixo custo. (ALOVISI et al., 2017).

Tanto o nitrogênio $(\mathrm{N})$ como o potássio $(\mathrm{K})$ são os nutrientes mais exigidos pela soja, no caso do N, grande parte é suprida pelo solo (15 a 35\%) e a outra parte pela AGRARIAN ACADEMY, Centro Científico Conhecer - Goiânia, v.5, n.9; p. 1702018 
fixação simbiótica de $\mathrm{N}^{2}$ atmosférico (65 a $85 \%$ ). Apesar do fósforo (P) ser o menos extraído entre os três macronutrientes, nas adubações é utilizado em maior quantidade em virtude de grande parte ficar na forma indisponível para as plantas (OLIVEIRA et al., 2017).

A composição química da semente da soja, o vigor e metabolismo esta diretamente ligado à disponibilidade de nutrientes, sendo assim, o fornecimento adequado de nutrientes proporciona melhor desenvolvimento da planta, possibilitando a produção de metabólitos necessários para o desenvolvimento das sementes e frutos. (MONTEIRO et al., 2015). Dessa forma, o objetivo desse trabalho foi avaliar o desenvolvimento inicial da cultura da soja com o uso de diferentes doses de fertilizante $\mathrm{N}-\mathrm{P}-\mathrm{K}$, a fim de determinar a melhor dose dos fertilizantes, de maneira que permita melhor aproveitamento dos nutrientes pela planta na fase inicial de desenvolvimento.

\section{MATERIAL E MÉTODOS}

O experimento foi realizado no período de 25 de outubro a 25 de novembro de 2017 no Centro de Ciências Agrárias e da Biodiversidade (CCAB) da Universidade Federal do Cariri (UFCA), localizada no município de Crato, Ceará, com as coordenadas geodésicas $7^{\circ} 14^{\prime} 49^{\prime \prime S}, 39^{\circ} 22^{\prime} 05^{\prime W}$ e 414 metros de altitude. A região tem um clima tropical úmido com inverno seco e estação chuvosa de novembro a abril (verão) e estação seca de maio a outubro (inverno), que corresponde à classificação climática Aw de Köeppen. Geralmente as precipitações são superiores a $750 \mathrm{~mm}$ anuais nas regiões de clima Aw', esse clima também é encontrado no litoral e serras do Ceará (EMBRAPA, 2014).

O solo é classificado como Argissolo Vermelho Amarelo, de textura arenosa, conforme a classificação de solos de média intensidade da FUNCEME (2012). A constituição química na camada de $0-20 \mathrm{~cm}$ foi: $\mathrm{pH}(1: 2,5 \mathrm{H} 2 \mathrm{O}): 4,9$; $\mathrm{P}$ (melich-1): 6,3 $\mathrm{mg} \mathrm{dm}{ }^{-3}$; K: $1,28 \mathrm{mmolc} \mathrm{dm}^{-3}$; Ca: 7,9 mmolc $\mathrm{dm}^{-3}$; $\mathrm{Mg}: 5,6 \mathrm{mmolc} \mathrm{dm}^{-3}$; CTC: 33,8 mmolc $\mathrm{dm}^{-3}$ e V (\%): $45 \%$.

O delineamento experimental utilizado foi em blocos casualizados, com quatro tratamentos e oito repetições, totalizando 32 parcelas experimentais. Os tratamentos consistiram em quatro doses de nitrogênio, fósforo e potássio (N-P-K) que foram aplicados na semeadura da soja, com valores de 0, 25, 50 e 100\% da dose recomendada para a cultura. Cada parcela experimental ocupou uma área de $4,5 \mathrm{~m}^{2}$, correspondente a três fileiras de soja com três metros de comprimento e espaçadas a 0,45 metros entre si. A fileira central foi considerada como a parcela útil com um metro de comprimento, este foi o mesmo local da coleta das plantas para análise.

No dia 05 de setembro de 2017 foi realizada a calagem, a fim de elevar a saturação por bases para $70 \%$. Posteriormente foram realizadas duas gradagens para incorporar o calcário. A instalação do sistema de irrigação por micro aspersão foi realizada dia 11 de setembro, com um período de rega diário para suprir a demanda da cultura, com uma lâmina diária de $6 \mathrm{~mm}$. A área permaneceu em pousio por um mês e 20 dias para esperar a correção da acidez do solo.

No dia 25 de outubro foi realizada uma gradagem leve na área para o preparo do solo. Posteriormente, fez-se os sulcos espaçados a $0,45 \mathrm{~m}$, com $0,1 \mathrm{~m}$ de profundidade. Vale destacar que foram utilizados adubos simples para essa operação em função de não existir fórmula comercial compatível.

AGRARIAN ACADEMY, Centro Científico Conhecer - Goiânia, v.5, n.9; p.171 2018 
Dessa forma, na adubação de fundação foram utilizados $20 \mathrm{~kg} \mathrm{ha}^{-1} \mathrm{de} \mathrm{N}, 70 \mathrm{~kg}$ ha ${ }^{-1}$ de $\mathrm{P}_{2} \mathrm{O}_{5}$ e $40 \mathrm{~kg} \mathrm{ha}^{-1}$ de $\mathrm{K}_{2} \mathrm{O}$ nos tratamentos em que tinha dose de $100 \%$. As doses utilizadas sofreram variações proporcionais em relação a esta dose, de acordo com os tratamentos.

Foi utilizada a cultivar M8349 IPRO, pois a mesma apresenta elevado potencial produtivo, com ampla adaptação geográfica, excelente arquitetura de planta e alta estabilidade. O espaçamento utilizado no plantio foi de $8 \mathrm{~cm}$ entre sementes, totalizando uma densidade de 277.778 sementes ha ${ }^{-1}$. As plantas foram colhidas da parcela útil aos 30 DAS para a análise do desenvolvimento inicial das plantas, para serem avaliadas as variáveis comprimento da raiz, altura da planta, massa da parte aérea da raiz e total, número de folhas.

A altura das plantas foi medida da superfície do solo até o ápice do ramo principal com uso de trena. A massa da parte aérea e das raízes foi medida em balança semianalítica de precisão, com três casas decimais para gramas. O comprimento da raiz foi medido considerando a raiz principal e foi realizada com uma trena. A massa total foi a soma da massa de raízes e da parte aérea. Os dados foram tabulados e submetidos à análise de variância e à análise de regressão para seleção do maior expoente significativo, utilizando-se o programa estatístico SISVAR 5.3 (FERREIRA, 2010).

\section{RESULTADOS E DISCUSSÃO}

De acordo com a análise de variância dos dados encontrados no presente trabalho (Tabela 1), a massa da parte aérea de cinco plantas (MA), massa da raiz de cinco plantas (MR) e massa total de cinco plantas (MT) não apresentaram valores significativos pelo teste $\mathrm{F}$, obtendo-se médias gerais de, respectivamente, $35 \mathrm{~g}, 6,96 \mathrm{~g} \mathrm{e}$ $41,96 \mathrm{~g}$.

TABELA 1. Síntese da análise de variância e do teste de médias para massa da parte aérea de 5 plantas (MA), massa da raiz de 5 plantas (MR) e massa total de 5 plantas (MT).

\begin{tabular}{lllll}
\hline \multirow{2}{*}{ Fontes de Variação } & \multirow{2}{*}{ G.L. } & \multicolumn{2}{l}{ Quadrados Médios } & \\
\cline { 3 - 5 } & & MA & MR & MT \\
\hline Bloco & 7 & $84,59^{\mathrm{NS}}$ & $4,14^{\mathrm{NS}}$ & $118,44^{\mathrm{NS}}$ \\
Adubo (A) & 3 & $730,63^{\mathrm{NS}}$ & $9,23^{\mathrm{NS}}$ & $876,08^{\mathrm{NS}}$ \\
Resíduo & 21 & 268,71 & 7,04 & 345,92 \\
\hline CV $(\%)$ & - & 46,83 & 38,12 & 44,32 \\
\hline Média Geral & - & $35 \mathrm{~g}$ & $6,96 \mathrm{~g}$ & $41,96 \mathrm{~g}$ \\
\hline
\end{tabular}

NS: não significativo; CV\%: coeficiente de variação.

Porém, apesar de não ter significância pela análise de variância, quando submetida análise de regressão, a variável massa aérea apresentou resposta quadrática significativa a 5\% (Figura 1), com o pico de produção em torno de $43 \mathrm{~g} \mathrm{com}$ o uso de $55,9 \%$ da dose de adubação recomendada. Resultado que confirma a afirmação de Guareschi et al. (2011) que dizem que a ausência de P e K e a aplicação AGRARIAN ACADEMY, Centro Científico Conhecer - Goiânia, v.5, n.9; p.172 2018 
de doses baixas desses nutrientes prejudica a produção de massa fresca.

Já Amaral e Rodrigues (2015) obtiveram resultados diferentes, afirmando que a carência de $\mathrm{P}$ e K (Testemunha) e aplicações de baixas doses desses nutrientes prejudicam a produção de massa fresca e produtividade da soja, com uma dosagem de $50 \%$ da recomendada para a adubação proporcionando resultados parecidos com o da testemunha, demostrando resultados insatisfatórios para tais adubações.

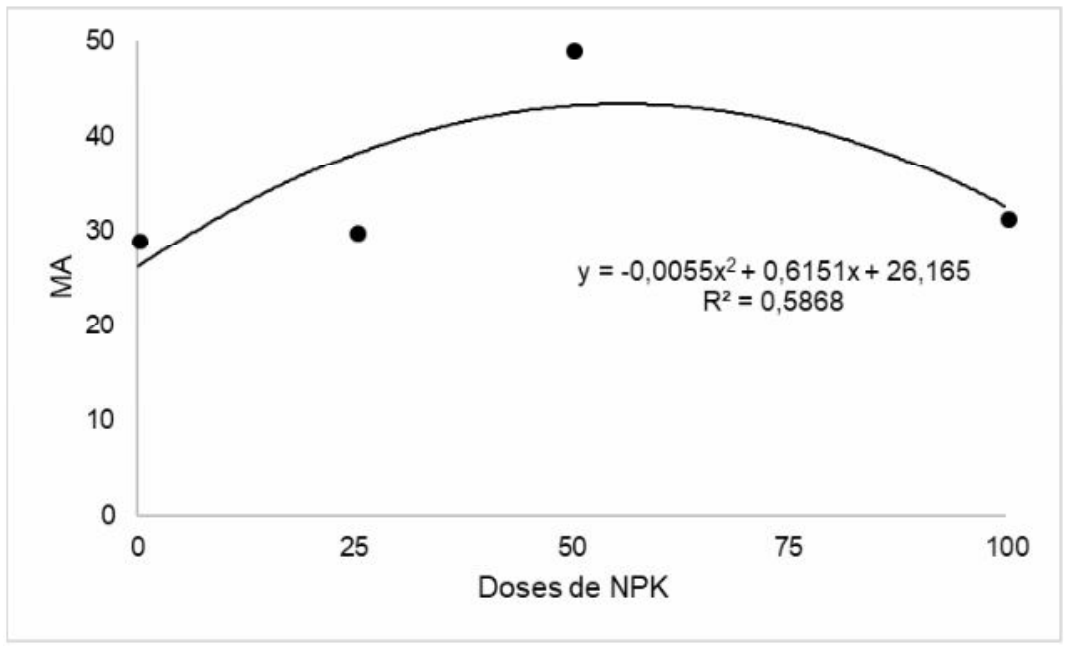

FIGURA 1. Análise de regressão para a massa da parte aérea (MA) em função das doses de adubação com N-P-K.

$\mathrm{Na}$ Figura 2, a massa total apresentou resposta quadrática significativa a $5 \%$ de probabilidade, com o pico de produção com cerca de $51 \mathrm{~g}$ com o uso de $54,4 \%$ da dose de adubação recomendada.

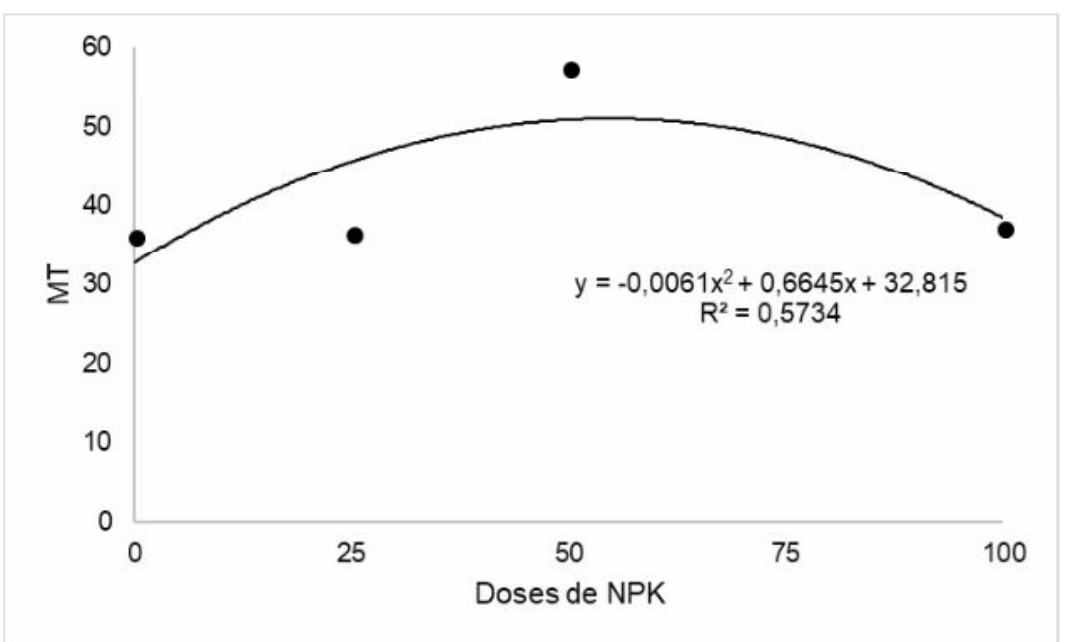

FIGURA 2. Análise de regressão para a massa total (MT) em função das doses de adubação com N-P-K. 
Em estudos, Padovan et al., (2005) evidenciaram que o acúmulo máximo da massa total ocorre no estádio $R$, envolvendo assim a parte reprodutiva e vegetativa e mesmo com uma perda de biomassa seca da parte vegetativa bem acentuada devido a da perca de folhas senescentes e da translocação de nutrientes para as sementes e vagens. Assim, pode-se constatar que doses de fertilizantes adequados possibilitam bom crescimento e desenvolvimento da soja, já doses abaixo ou acima do necessário limitam o crescimento adequado. Observando que o pico máximo de produção da massa total é praticamente igual ao pico máximo do número de folhas, com isso podese admitir que o maior número de folhas proporcionou também aumento na massa total.

$\mathrm{Na}$ tabela 2, é possível observar que conforme a análise de variância dos dados encontrados neste trabalho os fatores altura de cinco plantas (Altura) e comprimento da raiz de cinco plantas $(\mathrm{CR})$ também não apresentaram valores significativos pelo teste $\mathrm{F}$ com respectivas médias gerais de 13,16 e $17,95 \mathrm{~cm}$, resultado diferente para a altura de plantas dos obtidos por Carvalho et al. (2011) que foram significativamente influenciadas pelas doses do fertilizante mineral. O número de folhas de cinco plantas (NF), foi significativo a $5 \%$ e obteve média geral de 18,95 folhas.

TABELA 2. Síntese da análise de variância e do teste de médias para altura da planta (Altura), o comprimento da raíz (CR) e o número de folhas por planta (NF).

\begin{tabular}{lllll}
\hline \multirow{2}{*}{ Fontes de Variação } & \multirow{2}{*}{ G.L. } & & \multicolumn{3}{l}{ Quadrados Médios } \\
\cline { 3 - 5 } & & Altura & CR & NF \\
\hline Bloco & 7 & $2,36^{\mathrm{NS}}$ & $3,25^{\mathrm{NS}}$ & $11,88^{\mathrm{NS}}$ \\
Adubo (A) & 3 & $6,61^{\mathrm{NS}}$ & $9,40^{\mathrm{NS}}$ & $71,99^{*}$ \\
Resíduo & 21 & 5,11 & 4,48 & 23,31 \\
\hline CV $(\%)$ & - & 17,18 & 11,8 & 25,48 \\
\hline Média Geral & - & $13,16 \mathrm{~cm}$ & 17,95 & 18,95
\end{tabular}

*: significativo $(\mathrm{P}<0,05)$; NS: não significativo; CV\%: coeficiente de variação.

Na Figura 3, o número de folhas apresentou resposta quadrática significativa a $5 \%$, com o pico de produção de aproximadamente 21 folhas com 52,4\% da dose de adubação recomendada. Silva et al. (2009) afirmam que o número de folhas está inteiramente ligado com a área foliar. Sendo assim, maior área foliar pode ser referida a um maior número de folhas, e não só com o aumento da área foliar que já existe na planta. Percebe-se que as variáveis da parte aérea da soja operam em conjunto com o desenvolvimento maior da planta da soja.

Pereira et al. (2016) relatam que o potássio tem como principal função na planta ser ativador enzimático, e também de realizar função fisiológica fundamental no fechamento e abertura de estômatos, tendo assim um efeito direto na formação de folhas. 


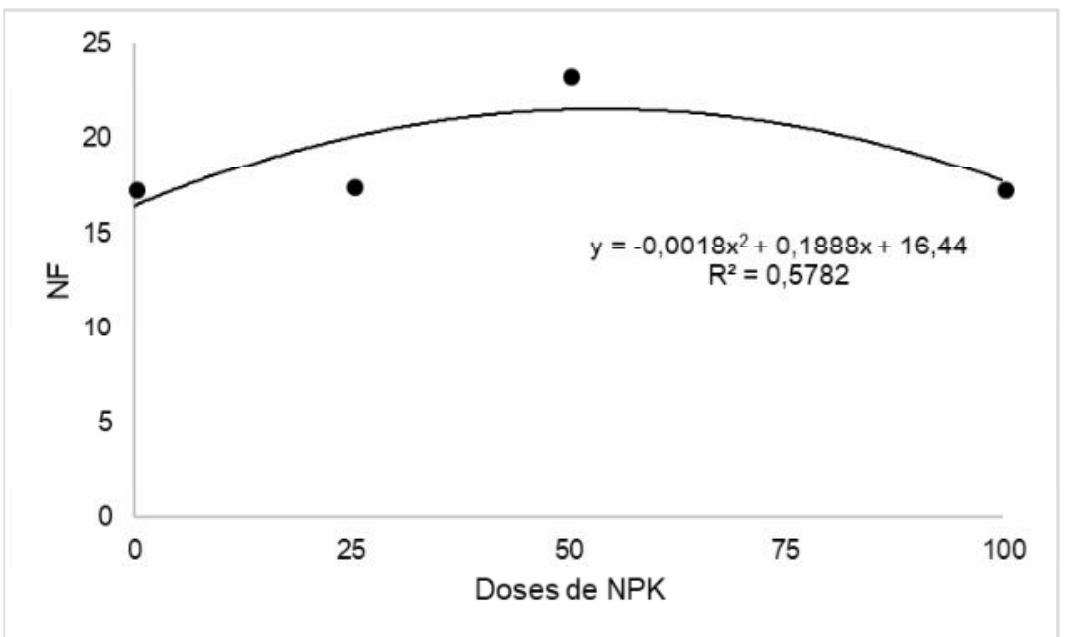

FIGURA 3. Análise de regressão para o número de folhas (NF) em função das doses de adubação com N-P-K.

\section{CONCLUSÃO}

Para as condições em que foi realizada a pesquisa, concluiu-se que a aplicação entre 50 a $60 \%$ da dose de adubação recomendada com N-P-K proporcionou o melhor desenvolvimento inicial da soja, com aumento na massa da parte aérea e total, além do número de folhas das plantas.

\section{AGRADECIMENTOS}

À Universidade Federal do Cariri e ao Programa de Educação Tutorial (PET) da Agronomia pela concessão da área experimental e das bolsas de estudo que possibilitaram o desenvolvimento desta pesquisa.

\section{REFERÊNCIAS}

ALOVISI, A. M. T.; FRANCO, D.; ALOVISI, A. A.; HARTMANN, C. F.; TOKURA, L. K.; SILVA, R. S. Atributos de fertilidade do solo e produtividade de milho e soja influenciados pela rochagem. II Seminário de Engenharia de Energia na Agricultura Acta Iguazu. v. 6, n. 5, p. 57-68, 2017. Disponível em: <http://erevista.unioeste.br/index.php/actaiguazu/article/view/18470/12057>.

AMARAL, U.; RODRIGUES, F. P. Aspectos produtivos e econômicos da soja sob adubação suplementar em áreas de pivô central. Multi-Science Journal. v.1, n.3, p.2430 , 2015. <https://www.ifgoiano.edu.br/periodicos/index.php/multiscience/article/download/97/82>.

CARVALHO, E. R; REZENDE P. M; ANDRADE, M. J. B; PASSOS A. M. A; OLIVEIRA J. A. Fertilizante mineral e resíduo orgânico sobre características agronômicas da soja e nutrientes no solo. Revista Ciência Agronômica. v. 42, n. 4, p. 930-939, out-dez, 2011. Disponível em <http://www.scielo.br/scielo.php?pid=S1806$66902011000400015 \&$ script=sci_abstract\&tIng=pt $>$. 
EMBRAPA. Tecnologia de produção de soja - Região Central do Brasil 2014. Disponível em: <https://www.embrapa.br/busca-de-publicacoes//publicacao/975595/tecnologias-de-producao-de-soja---regiao-central-do-brasil-2014>.

FERREIRA, D. F. 2010. Sistema de análise SISVAR - de variância. Versão 5.3. Lavras-MG: UFLA. Disponível em $<$ https://www.scienceopen.com/document?vid=23142c40-1b65-4ceb-a47a2263b443739d>.

FIORIN, J. E.; VOGEL, P. T; BORTOLLOTO, R. P. Métodos de aplicação e fontes de fertilizantes para a cultura da soja. Agrária - Revista Brasileira de Ciências Agrárias. v.11, n.2, $\quad$ p.92-97, 2016.2 Disponível em: <http://www.redalyc.org/html/1190/119046408005/>. DOI:10.5039/agraria.v11i2a5371.

FUNCEME - Fundação Cearense de Meteorologia e Recursos Hídricos. 2012. Levantamento de reconhecimento de média intensidade dos solos da Mesorregião do Sul Cearense / Fundação Cearense de Meteorologia e Recursos Hídricos. Fortaleza. Disponível em: < $\mathrm{ftp}: / /$ ftp.funceme.br/Meio_ambiente/ZACE/tmp/folha/folhas.6.pdf>. Acesso em: $10 \mathrm{de}$ julho de 2018.

GUARESCHI, R. F.; GAZOLLA, P. R.; PERIN, A., \& SANTINI, J. M. K. Adubação antecipada na cultura da soja com superfosfatotriplo e cloreto de potássio revestidos por polímeros. Ciência Agrotecnologia Lavras. v. 35, n. 4, p. 643-648, jul./ago, 2011. Disponível

em <http://www.academia.edu/24036160/Aduba\%C3\%A7\%C3\%A3o_antecipada_na_cultur a_da_soja_com_superfosfato_triplo_e_cloreto_de_pot\%C3\%A1ssio_revestidos_por_po $1 \%$ C3\%ADmeros $>$.

MONTEIRO, A. N. L.; ALVES, J. M. A.; MATOS. W. S.; SILVA. M. R.; SILVA. D. L.; BARRETO. G. F. Densidade de plantas e doses de NPK nos componentes de produção de soja-hortaliça na Savana de Roraima. Original Revista Agro@mbiente On-line. v. 9 , n. 4, p. 352-360, outubro-dezembro, 2015. Disponível em <https://revista.ufrr.br/agroambiente/article/view/2638/1872>. DOI: 10.18227/19828470ragro.v9i4.2638.

OLIVEIRA, J. G.; SILVA, V. S. G.; COSTA. J. P. V. Comportamento de soja submetida a materiais fertilizantes e inoculação com bradyrhizobium. Revista da Universidade Vale do Rio Verde, Três Corações. v. 15, n. 1, p. 66-72, jan./jul. 2017. Disponível em <http://periodicos.unincor.br/index.php/revistaunincor/article/view/3016>. DOI: http://dx.doi.org/10.5892/ruvrd.v15i1.3016.

PADOVAN, M. P.; ALMEIDA, D. L.; GUERRA, J. G. M.; ALVES, A. J. R.; RIBEIRO, R. L. D.; OLIVEIRA, F. L.; SANTOS, L. A.; SOUTO, S. M. Indicadores agronômicos do potencial da soja (Cv. Celeste) para fins de adubação verde de verão. Revista AGRARIAN ACADEMY, Centro Científico Conhecer - Goiânia, v.5, n.9; p.176 2018 
Cientifica Pesquisa Agropecuária Gaúcha, Porto Alegre. v. 11, n. 1-2, p. 47-54, 2005. Disponível em < http://www.fepagro.rs.gov.br/upload/1398796932_art06.pdf>.

PEREIRA, C. S.; FREITAS, A. A.; CHAPLA, M. V.; L, A. Doses de potássio com a presença de enxofre na cultura da soja. Global science and technology, Rio Verde. v.09, n.01, p.22 - 32, jan/abr. 2016. Disponível em $<$ https://rv.ifgoiano.edu.br/periodicos/index.php/gst/article/view/784>.

SANTOS, C. G.; MARTINS, G. L. M.; SILVA, P. A.; ZOZ, T. Custo de produção de soja transgênica em sistema de semeadura direta em São Desidério-BA. Revista de Agricultura Neotropical. v. 4, n. 2, p. 96-101, abr./jun. 2017. Disponível em: $<$ https://periodicosonline.uems.br/index.php/agrineo/article/download/1430/1397>.

SILVA, A. F.; CONCENÇO, G.; ASPIAZÚ, I., FERREIRA, E. A.; GALON, L.; COELHO, A. T. C. P.; SILVA, A. A.; FERREIRA, F. A. Interferência de plantas daninhas em diferentes densidades no crescimento da soja. Planta Daninha. v. 27, n. 1, p. 75-84, 2009. Disponível

<https://rv.ifgoiano.edu.br/periodicos/index.php/gst/article/download/91/106>. 